\title{
Metagenomic approach for the isolation and cultivation of cellulose- degrading myxobacteria
}

\author{
Ronald Garcia $^{1,2^{*}}$, and Rolf Müller ${ }^{1,2}$
}

\begin{abstract}
Cellulose-degrading myxobacteria are common soil microorganisms with unique morphologies and are united forming the distinct Sorangium and Byssovorax clades in the Polyangiaceae family, order Myxococcales. Cells of these fascinating bacteria can glide, form fruiting bodies and degrade agar and cellulose. However, phenotypic studies based on the swarm, fruiting bodies and cellulose degradation pattern have shown many dissimilarities among strains suggesting more potential to identify new species in Sorangium clade. Currently, nine validly described species are recognized capable of decomposing cellulose in myxobacteria, of which eight species belong to the genus Sorangium and one species to Byssovorax. With the increasing number of species recently validated in Sorangium, likely there will also be more species of Byssovorax that can be found in the environment. BLAST search analysis of Byssovorax 16S rRNA gene sequences in NCBI public database (GenBank) revealed 97-98.8 \% similarity with sequences derived from clones of uncultured bacteria. In Sorangium, six 16S rRNA gene sequences derived from clones of uncultured bacteria were identified occupying novel branches and exhibiting 96.9\% - 98.6\% similarities with type strains. Molecular phylogenetic analysis confirmed the affiliations of these clones within Sorangium and Byssovorax clades, indicating potentially new species within these genera. Surprisingly, one sequence derived from a clone (DEN_SIP_103) may potentially represent a novel genus only if this strain can be successfully cultured in the future.
\end{abstract}

Keywords: myxobacteria, metagenomics, 16S rRNA gene, Sorangium, Byssovorax, cellulose-degradation

\section{Introduction}

The Myxobacteria (order Myxococcales) are regarded as one of the most highly evolved Gram-negative prokaryotes in the Delta Proteobacteria capable of producing complex fruiting bodies under nutrient-depriving condition. Many myxobacteria prey on microorganisms, which are used as a nutrient source for growth and multicellular development while some possess lytic enzymes for macromolecule degradation of cellulose, chitin, and agar. Due to the slow growth and difficulties in cultivation,

${ }^{1}$ Department of Microbial Natural Products (MINS), Helmholtz Institute for Pharmaceutical Research Saarland (HIPS) - Helmholtz Centre for Infection Research (HZI), Saarland University Campus Building C2 3, 66123 Saarbrücken, Germany

${ }^{2}$ German Center for Infection Research (DZIF), Partner site HannoverBraunschweig 38124, Germany

*Corresponding email: ronald.garcia@helmholtz-hips.de

Date Submitted: 24 August 2019

Date Accepted: 19 May 2020 very few laboratories around the world focus on exploring the diversity of myxobacteria. Although these bacteria are distributed worldwide in different environments, the soil appears to be the most common source for isolation. The tropical climate is considered abundant for myxobacteria and this is reflected in the species diversity in this region (Dawid, 2000).

The search for myxobacteria in the past decades was driven mainly by biotechnological applications for finding novel antibiotics and anti-cancer drugs (Shimkets et al., 2006; Reichenbach \& Dworkin, 1992), although it is not limited to these applications. Myxobacteria are also known for the production of steroids (Kohl et al., 1983; Zeggel, 1993; Gawas et al., 2011), diverse polyunsaturated fatty acids (Garcia et al., 2011; Gemperlein et al., 2014) and compounds with anti-viral (Plaza et al., 2012) and insecticidal activity (Kunze et al., 1993). The discovery of novel species, genera, and families in the last years has widened the understanding of myxobacterial biology, systematics and secondary metabolites (Garcia et al., 2010). Some of these myxobacterial isolates are regarded as facultative anaerobe (Sanford et al., 2002), microaerophile (Garcia et al., 2009; 2016), microaerotolerant (Garcia et al., 2018), obligate 
halophile (Iizuka et al., 1998; 2003a-b; Fudou et al., 2002; Ojika et al., 2008), and halotolerant (Iizuka et al., 2013).

To date, all validly described cellulose-degrading myxobacterial species are phylogenetically clustered in the genus Sorangium and Byssovorax. Between these two genera, Byssovorax seems rarely isolated and it appears with only one species and two strains are identified (Reichenbach 2005; Reichenbach et al., 2006). Byssovorax also seems to be a rare but interesting source of novel bioactive compounds in myxobacteria. So far, two novel natural compound families have been isolated in this genus and these include the antifungal and cytotoxic cruentaren (Kunze et al., 2006 - 2007), and the cytotoxic and antiviral macrolide haprolid (Steinmetz et al., 2016; Pietschmann et al., 2012). On the other hand, Sorangium is much established and can be considered a major producer of secondary metabolites among myxobacteria. The anticancer compound epothilone appears to be the most useful myxobacterial compound from Sorangium; it is became marketed by Bristol-Myers Squibb for the treatment of metastatic breast cancer (Mulzer, 2009).

Since cellulose-degrading myxobacteria are industrially valuable due to their medical applications, further studies to discover new species within producer genera and related taxa are highly motivated. To uncover potential new Sorangium species and determine the rarity of Byssovorax in the environment, BLAST search from the metagenomes in public databases (GenBank) was performed using the type species $16 \mathrm{~S}$ rRNA gene sequences.

\section{Isolation of cellulolytic myxobacteria and their phenotypic variations}

Cellulose-degrading myxobacteria are common organisms in soils with decaying plants. Isolation is based on baiting with filter paper on mineral salt agar (e.g. MS21, a modification of $\mathrm{Stan} 21$ ). MS21 contains (g per liter, w/v), $\mathrm{KNO}_{3} 0.5$, $\mathrm{MgSO}_{4} \cdot 7 \mathrm{H}_{2} \mathrm{O} 0.5, \mathrm{CaCl}_{2} \cdot 2 \mathrm{H}_{2} \mathrm{O} 0.5, \mathrm{FeCl}_{3}, 0.02, \mathrm{MnSO}_{4} \cdot 7 \mathrm{H}_{2} \mathrm{O}$ 0.1, HEPES 2.38, trace element solution (Drews, 1974) 100 $\mathrm{mL} / \mathrm{L}$, yeast extract 0.02 , Bacto agar $10, \mathrm{pH}$ adjusted to 7.0 with $\mathrm{KOH}$; supplemented with $\mathrm{K}_{2} \mathrm{HPO}_{4} 0.4$ after autoclaving (Garcia $\&$ Müller, 2014). Soil materials are placed on the edge of a filter paper and the plate culture is usually incubated for more than two weeks. They can also be isolated in ST21 agar containing $\mathrm{KNO}_{3}$ and filter paper (Reichenbach et al., 2005). Plain water agar baited with Escherichia coli is also used as a method for the isolation of Byssovorax cruenta; however, this appears doubtful due to a contrary statement that no growth was exhibited on this medium even if baited with filter paper (Reichenbach et al., 2006).
The cellulose-degrading myxobacteria can be recognized by the appearance of swarming and fruiting bodies on filter paper (Fig. 1a-1c). The swarm colony of Sorangium and Byssovorax can be identified by their cigar-shaped, nonflexuous, non-motile and phase-dark rods (Fig. 1d). Purification is commonly centered on fruiting bodies and swarming colony on mineral salts agar and Baker's yeast medium (e.g. VY/2 agar). Farthest and cleanest swarm edges are cut out while fruiting bodies can be clean by serially washing in drops of sterile water to decrease the adhering microbial contaminants. Unlike many myxobacteria, cellulose-degrading strains are much slow-growing and easily get contaminated, thus the use of antibiotics is sometimes necessary for the purification steps (Reichenbach, 1983; Reichenbach et al., 2006).

Cellulolytic myxobacteria are remarkable for their colors and patterns of filter paper decomposition (Fig. 2a-2d). Unlike Byssovorax, Sorangium exhibits variations in cellulose decomposition including shrinking of the filter paper (Fig. 2a), decomposition of cellulose fibers (Fig. 2b-2c) and to complete disappearance, and with of only fruiting bodies left (Fig. 2d). In mineral salts agar with filter paper strips, Byssovorax produces a hole in the paper as it swarms (Garcia \& Müller, 2014). Byssovorax also differs from Sorangium for its soft and veiny swarm which appears bloody red on filter paper and agar (Fig 3a -3d). In some myxobacteria, the colors are associated with carotenoids (Jansen et al., 1995; Reichenbach \& Kleinig, 1971) and probably with their variants.

Sorangium produces different morphology patterns of sporangioles (Fig. 4a - 4d) and swarms (Fig. 5a-5d). Some strains show differences in color and sizes of sporangioles which could be arranged in chains (Fig. 4a), clusters (Fig. 4b-4d) or sometimes solitary. Some sporangioles are clustered compactly or loosely arrange in sori. The most common sporangiole color appears to be orange; black is quite rare (Fig. 4c). In general, Sorangium sporangioles are smaller compared with most myxobacteria. In S. cellulosum DSM $14627^{\mathrm{T}}$, sporangioles measure $20-30 \mu \mathrm{m}$ in diameter (Garcia \& Müller, 2014) while those in other strains of the same species are much bigger (e.g. $40-80 \mu \mathrm{m})$. In contrast, Byssovorax sporangioles are three to four times larger (80-140 $\mu \mathrm{m}$ diameter) than Sorangium.

The swarming pattern and morphology of Sorangium also vary. Swarms on agar may spread fast or slow, appear as nets (Fig. 5a), thick and branching veins (Fig. 5b) or as curtains or circular bands as in some members of family Polyangiaceae (Fig. 5c). Other strains form a tough and stringy swarm that often breaks, rips or cut the agar, and crumples the filter paper (Fig. 5d). In few strains, the swarm may appear deeply depressed in the agar as in some Nannocystis species (Fig. 5e); 


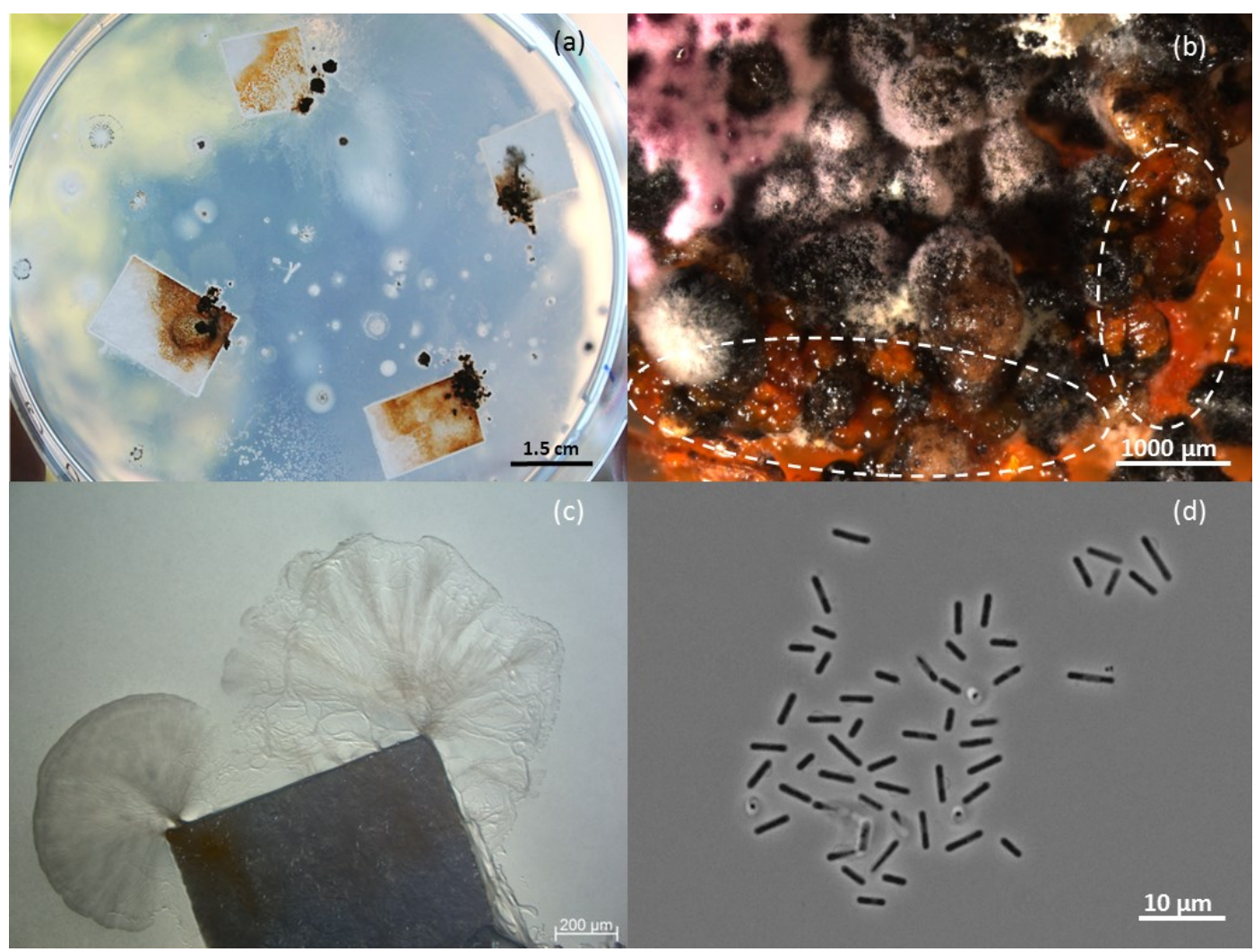

Figure 1. Recognition of cellulose-degrading myxobacteria. (a) Filter-paper baiting method inoculated with soil sample on MS21 mineral salts agar. In the presence of cellulose-degrading myxobacteria, paper usually became yellowish, reddish-orange, brownish, and black color due to the development of swarm and fruiting bodies. (b) The appearance of reddish-orange fruiting bodies (encircled) on filter paper and around the soil inoculum. It is also noticeable that this Sorangium strain is growing along with Actinomycetes-like colonies (pink and white powdery growth) on the soil sample. (c) Axenic culture of Sorangium showing the swarm stage coming out from the corners of filter paper. (d) Phase-dark and slender rods vegetative cells from the swarming colony.

this is in contrast to the more common strains showing thin swarms with plicate veins on agar (Fig. 5f).

Currently, Sorangium is classified into 8 species $-S$. cellulosum, S. ambruticinum, S. arenae, S. bulgaricum, $S$. dawidii, S. kenyense, S. orientale, S. reichenbachii (Mohr et al., 2019), but with no clear species distinction based on fruiting body, swarm morphology and phenotypic cellulose-degrading pattern. It would be interesting to determine whether the seven new added species differ in color, size, arrangement, and pattern of sporangiole using common lean media including VY/2 agar and mineral salt agar supplemented with filter papers that allow the development of those growth stages. It would also be interesting to compare among those species the swarms and degradation characteristics toward agar and cellulose.

Unlike Sorangium, Byssovorax rarely produces fruiting bodies (Reichenbach et al., 2006), but could be recognized by an intense bloody red swarm on filter paper and agar (Fig. 3a$3 b)$. None of the Sorangium species has ever been described to have this characteristic. Byssovorax has a slimy and soft swarm that makes the filter paper fiber thinner and fragmented after weeks of incubation (Fig. 3c-3d). The fruiting bodies it formed are much bigger and fewer compared with Sorangium.

The multi-locus gene and genome comparisons are becoming popular and helpful in describing new bacterial taxa; however, we believe that phenotypic characterizations are as well important, especially in myxobacteria with unique morphology features.

\section{Potential for discovery of novel cellulose-degrading myxobacteria}

There is no doubt that new species of Sorangium and Byssovorax or other cellulose-degrading myxobacteria can be found in the future. Based on BLAST searches, several uncultured bacteria appear related to cellulose-degrading myxobacteria (Table 1). Most of these clones were derived from soils commonly associated with vegetations (Ceja-Navarro et 
Table 1. Clones derived from uncultured bacteria that are phylogenetically related with Sorangium and Byssovorax based on 16S rRNA gene sequence. The sequences were found by BLAST searches using the GenBank accession numbers. Clones No. 1-4, neighbor with Byssovorax; Clones No. 6-11, neighbor with Sorangium; Clone 5 neighbors to both cellulose-degrading genera.

\begin{tabular}{|c|c|c|c|c|c|}
\hline No. & Clone & $\begin{array}{c}\text { GenBank } \\
\text { Accession No. }\end{array}$ & Source & Country & Reference \\
\hline 1 & S137 & DQ083111 & soil & not specified & Unpublished \\
\hline 2 & AKYG1042 & AY921777 & $\begin{array}{l}\text { farm soil adjacent to a silage storage } \\
\text { bunker }\end{array}$ & Minnesota, USA & Tringe et al., 2005 \\
\hline 3 & KGB200711-089 & EU881272 & serious disturbance field soil & Guangxi, China & Unpublished \\
\hline 4 & $\operatorname{ncd} 2523 \mathrm{~b} 10 \mathrm{c} 1$ & JF217095 & human skin & Washington, USA & Kong et al., 2012 \\
\hline 5 & DEN_SIP_103 & KF533828 & full-scale EBPR activated sludge plant & Denmark & Unpublished \\
\hline 6 & B8-157 & KF494619 & permafrost soil & $\begin{array}{l}\text { Qinghai-Tibet Plateau, } \\
\text { China }\end{array}$ & Unpublished \\
\hline 7 & Plot21-H07 & EU193074 & agricultural soil & Mexico & $\begin{array}{c}\text { Ceja-Navarro et al., } \\
2010\end{array}$ \\
\hline 8 & Ip 167 & KC331385 & apple orchard & Loess Plateau, China & Chen et al., 2014 \\
\hline 9 & p25i20ok & FJ479176 & undisturbed tall grass prairie, top $5 \mathrm{~cm}$ & $\begin{array}{l}\text { Kessler Farm, Oklahoma, } \\
\text { USA }\end{array}$ & Youssef et al., 2009 \\
\hline 10 & $\mathrm{FFCH} 2381$ & EU134329 & $\begin{array}{l}\text { soil from an undisturbed mixed grass } \\
\text { prairie preserve }\end{array}$ & $\begin{array}{l}\text { Kessler Farm, Oklahoma, } \\
\text { USA }\end{array}$ & Elshahed et al., 2008 \\
\hline 11 & 1112842459896 & HQ119466 & loamy sand of Eucalyptus forest & La Jolla, California, USA & $\begin{array}{l}\text { Williamson et al., } \\
2011\end{array}$ \\
\hline
\end{tabular}




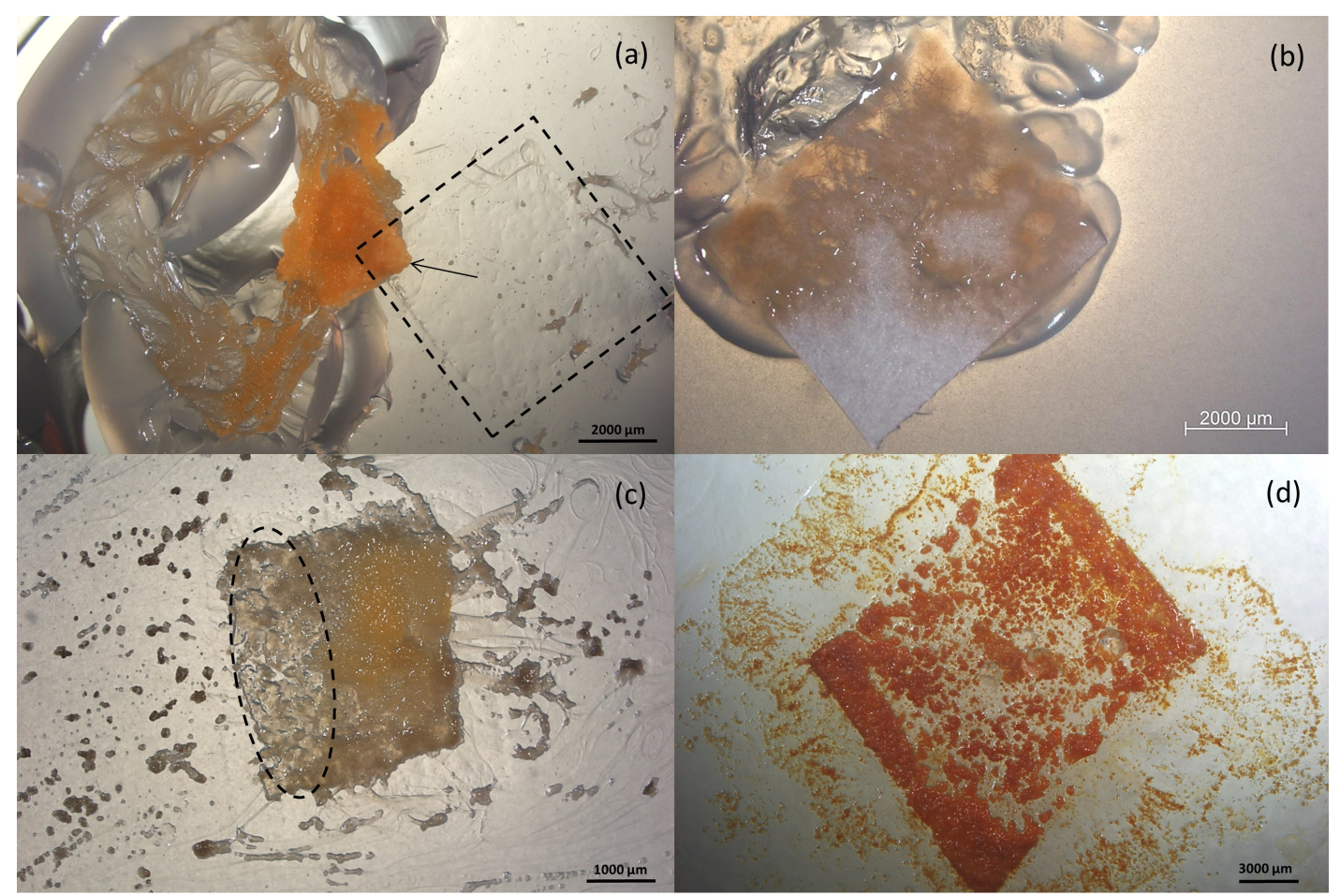

Figure 2. Patterns of cellulose degradation in Sorangium. (a) Filter paper is retracted from the agar and crumpled by a stringy and tough swarm. The dotted line enclosed the imprint area of retracted paper (arrow) on agar. Remarkable cuts and breaks in agar can also be recognized in this culture. (b) Strain GT $-47^{\top}$ cellulose degradation along the edges and towards the center of the paper. (c) Filter paper becomes soft, slimy and loosing of the filter fibers (encircled). Yellow cell aggregations are also formed on the paper while brownish-black fruiting bodies can be seen around the paper. (d) Complete cellulose degradation with only fruiting bodies remained to form the shape of a filter paper. Reddish-orange fruiting bodies are also formed closed to the paper and on the agar.

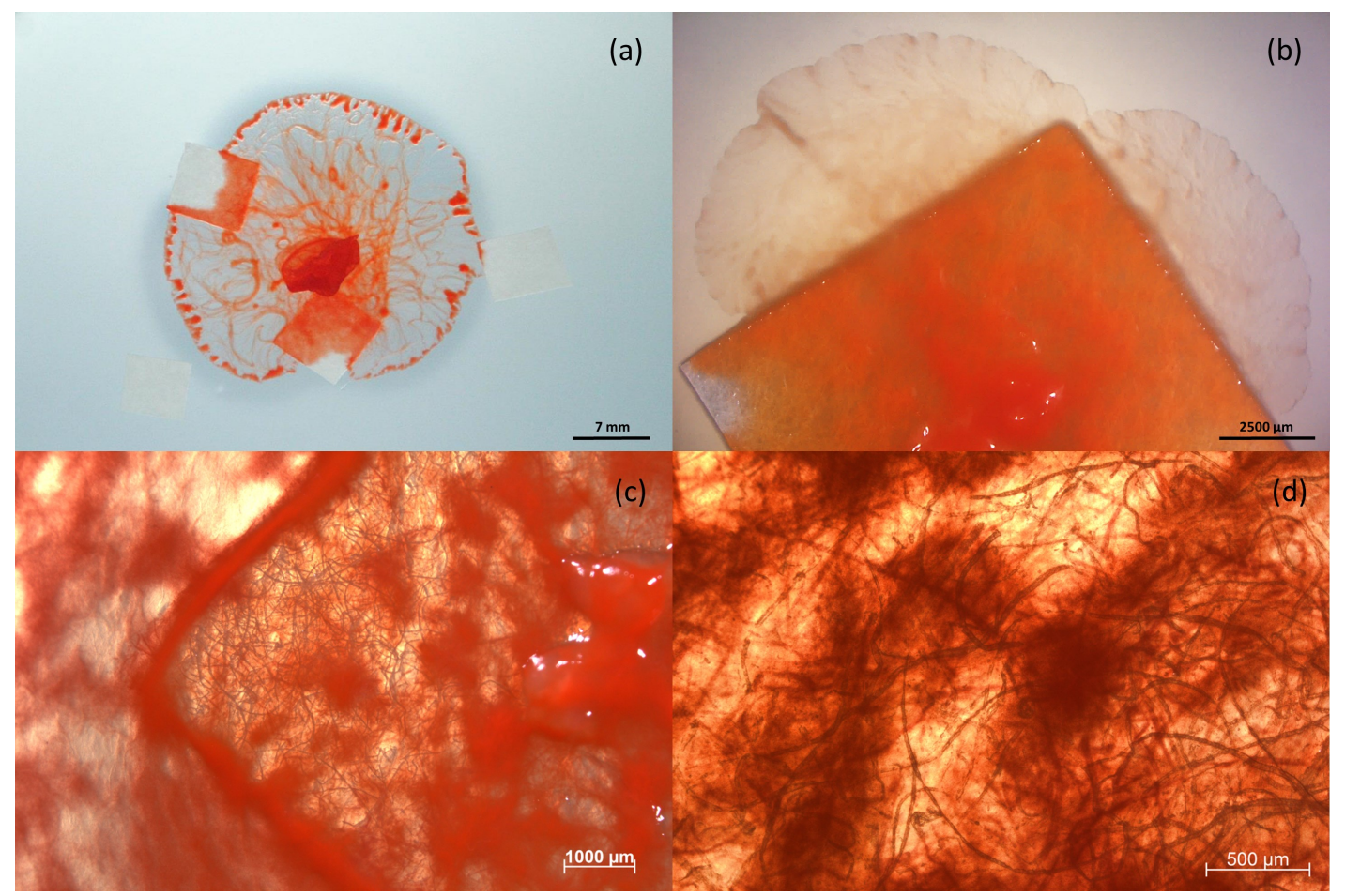

Figure 3. Growth of Byssovorax cruenta on VY/2 agar supplemented with maltose. (a) Intense bloody red colony swarming veins on agar and filter paper. (b) Swarms coming out from the edges of a paper. (c) Degradation of cellulose marked by thinning of the paper and showing ripped cellulose fibers. (d) Magnified view of the filter paper showing the fragmentations of the cellulose strands as an implication of degradations. 


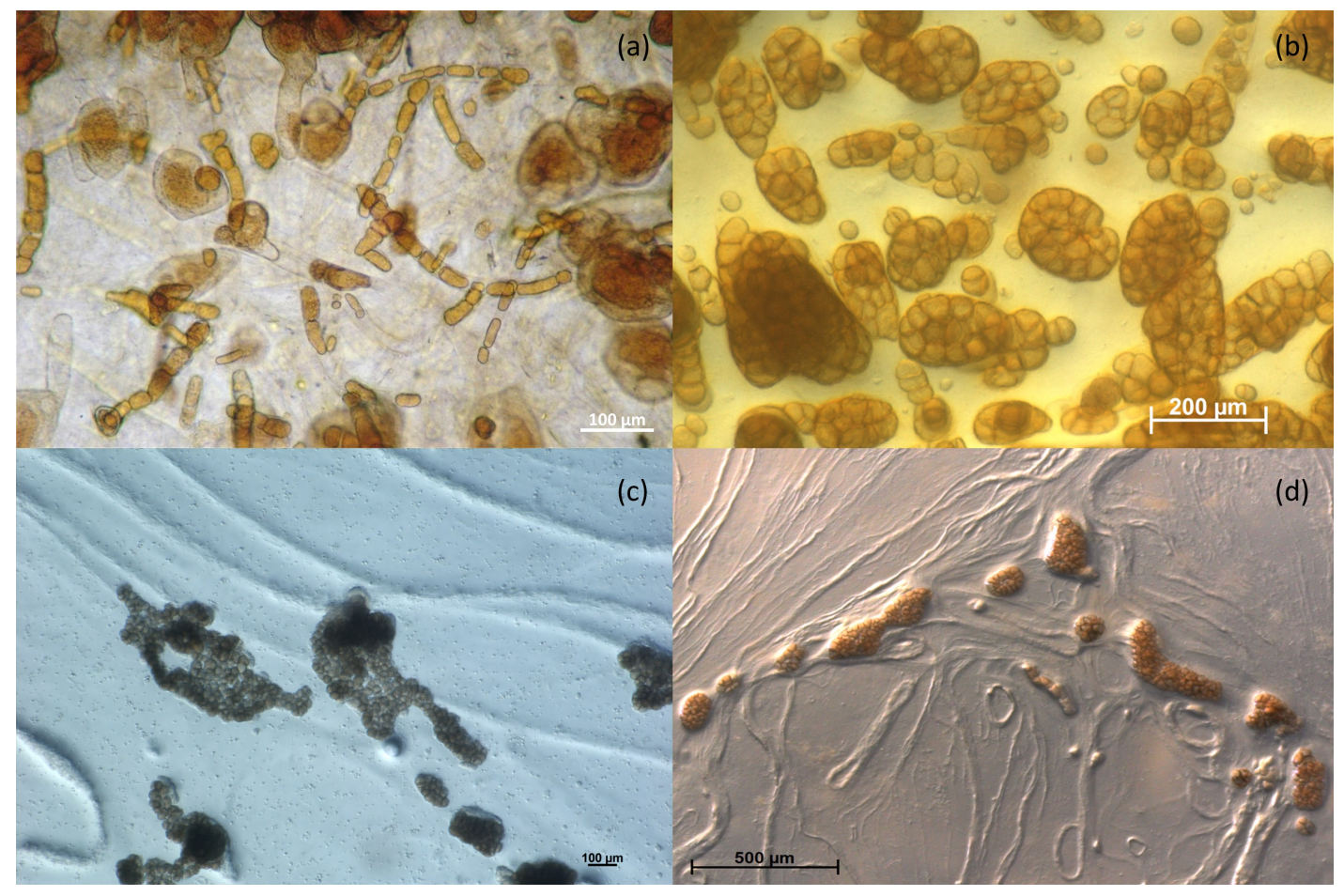

Figure 4. Fruiting body variations in some Sorangium strains. (a) Sporangioles appearing mostly as chains in decomposed filter-paper strands. (b) Fruiting bodies compactly arranged as clusters in a completely decomposed filter paper. (c) Black and tiny fruiting bodies on an agar. (d) Mounds of compactly arranged brownish fruiting bodies along with the veiny swarm.

al., 2010; Chen et al., 2014; Elshahed et al., 2008; Williamson et al., 2011; Youssef et al., 2009). This is not surprising since soil is the known habitat for Sorangium and Byssovorax. Surprisingly, clone ncd2523b10c1 (GenBank Accession number: JF217095) from a human skin associated with atopic dermatitis (Kong et al., 2012) turned out to be $98.6 \%$ similar in the 16S rRNA gene sequence with B. cruenta By $\mathrm{c}^{\mathrm{T}}$ and phylogenetically positioned within the Byssovorax clade (Fig. $6)$. Whether the uncultured bacterial clone ncd2523b10c1 represents just a random occurrence on the skin, a contaminant or even a potential agent to cause disease in humans needs further investigations once this bacterium becomes cultivable under laboratory conditions. So far, none of the isolated and validly described myxobacteria is known to cause any disease in humans.

An indication that cellulose-degrading myxobacteria exist in the extreme environment was based on the metagenomic sequence (clone B8-157, GenBank Accession number KF494619) amplified from a Tibetan Plateau permafrost soil. Based on the 16S rRNA gene phylogenetic analysis, clone B8157 was determined clustered within Sorangium clade and appeared closely related (97.6\% similarity) with $S$. orientalis Soce $\mathrm{GT}_{4} 7^{\mathrm{T}}$ and $S$. arenae Soce $1078^{\mathrm{T}}$. Since clone B8-157 occupied a novel branch and showed a $2.4 \%$ difference in the
16S rRNA gene sequence, it appears to be a representative of a novel Sorangium species after its successful cultivation in the future.

So far, we have found 10 16S rRNA gene sequences (Table 1), all from uncultured bacteria that appear to be related (96.9\% - 98.8\% similarity) with Sorangium and Byssovorax after molecular phylogenetic analysis (Fig. 6). Clones 1-4 (GenBank accession numbers: DQ83111, AY921777, EU881272, JF217095) show 97-98.8 \% similarity with Byssovorax while clones 6-11 (GenBank accession numbers: KF494619, EU193074, KC331385, FJ479176, EU134329, HQ119466) exhibit 96.9\% - 98.6\% similarity with Sorangium. On the other hand, clone 5 (DEN_SIP_103, GenBank accession number: KF533828) from an activated sludge plant in Denmark shows lower similarity (95.2\%-95.9\%) with Sorangium and Byssovorax type strains and appears positioned in between these two genera. Clone DEN_SIP_103 possibly represents a novel cellulose-degrading genus in Polyangiaceae. By digging on the exact sourced samples as described in the metagenomic studies or by looking at the same type of samples, these uncultured myxobacteria may successfully be brought to cultivation someday. Exploration of various samples obtained from different environments may unexpectedly yield new species of Sorangium and Byssovorax or related cellulose-degrading taxa 


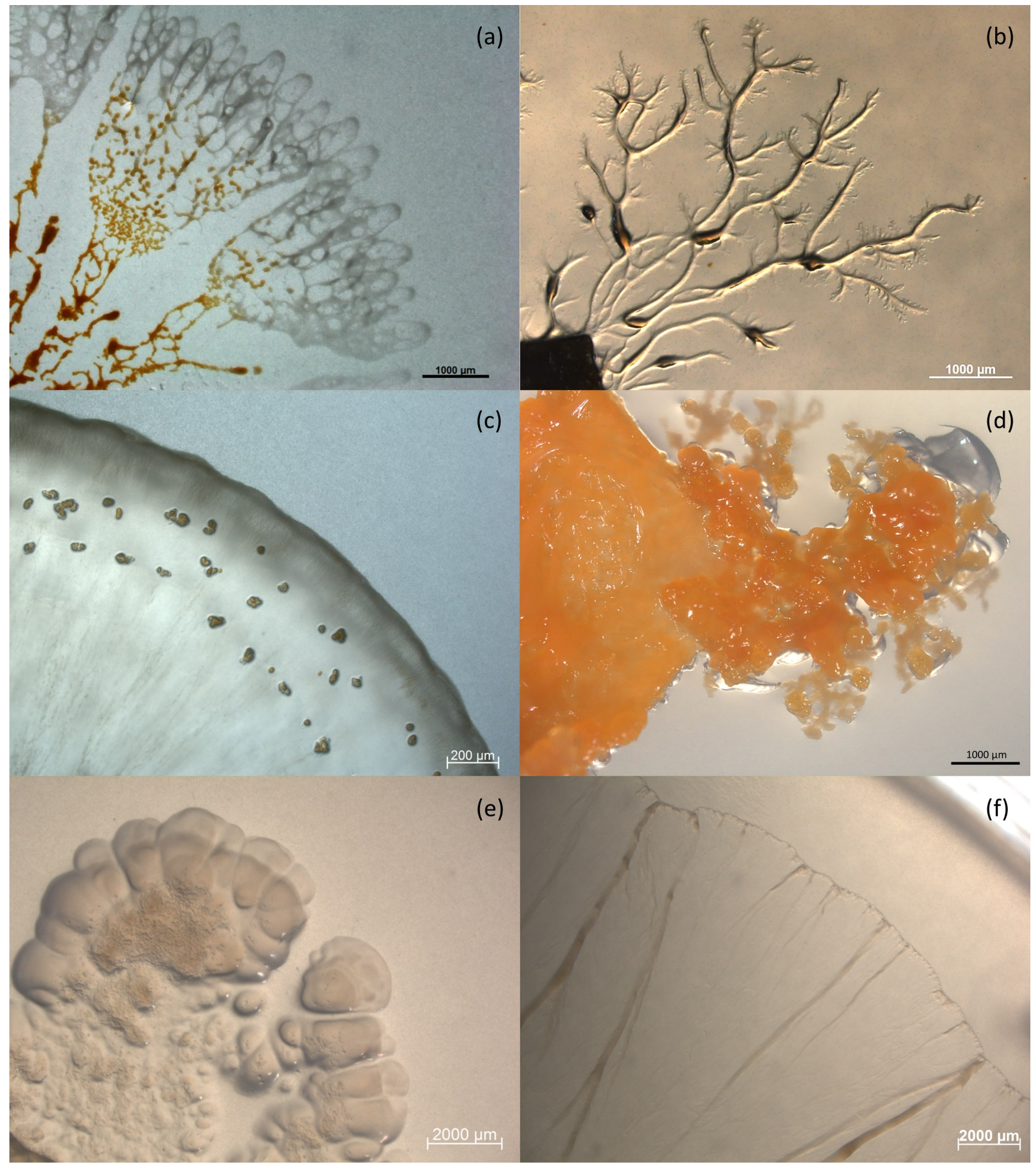

Figure 5. Sorangium swarming colony patterns in VY/2 medium baited with filter paper. (a) Netlike veins produced in agar and formation of fruiting bodies behind. (b) Long and branched veins appearing like plant roots on an agar. (c) Fan- or curtain-shaped colony in agar with the partial clearing of the yeast cells and formation of fruiting bodies towards the swarm edge. This reminds similarity with some members in Polyangiaceae. (d) Tough and extremely slow-spreading swarm colony causing cuts and ripping of the agar. (e) An unusual colony that grows deep into the agar and creating pits that show similarity with genus Nannocystis. (f) Fastspreading colony on agar marked by swarm plications and long veins. 


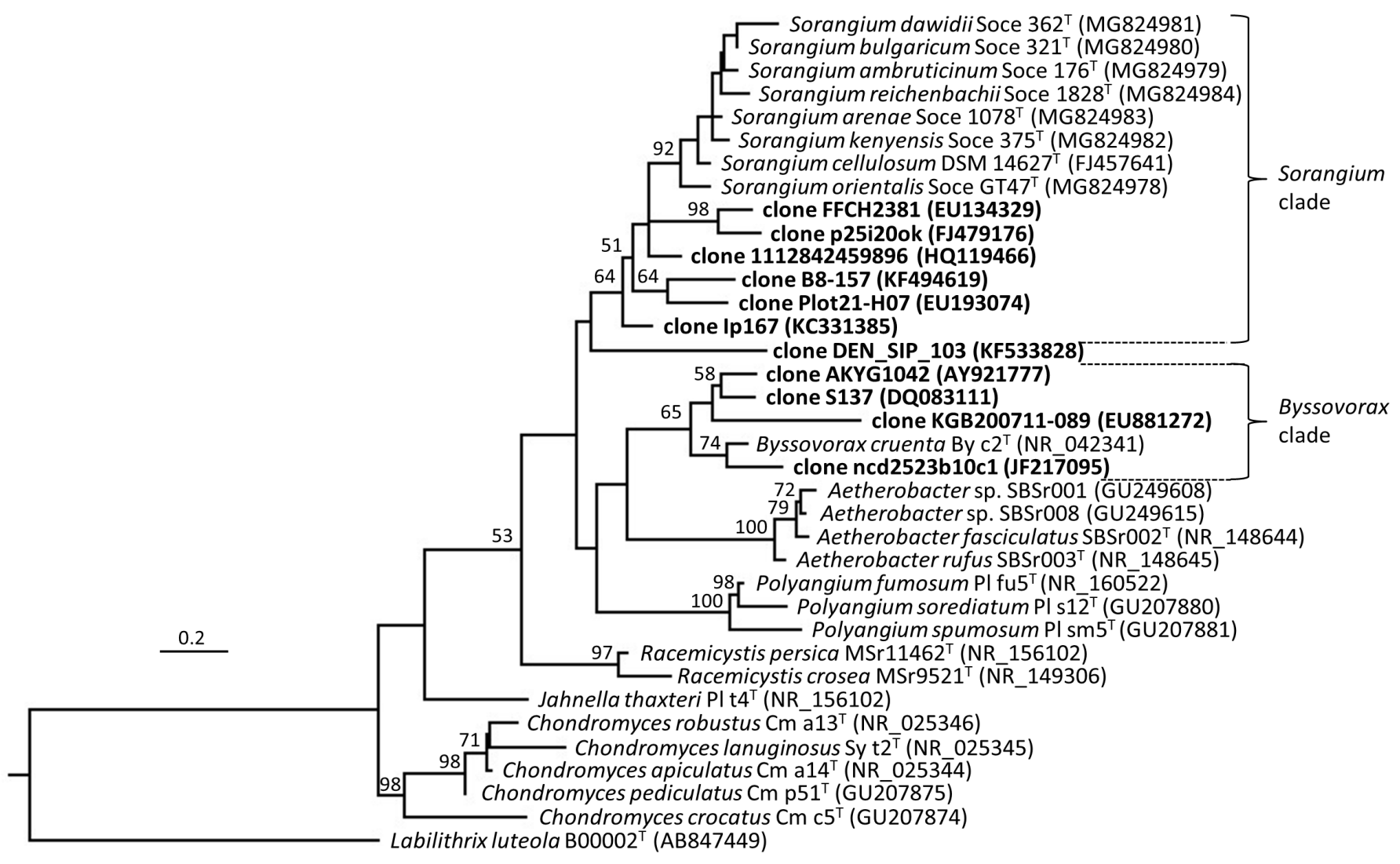

Figure 6. Maximum-likelihood phylogenetic tree inferred from 16S rRNA gene sequence showing the cellulose-degrading myxobacterial clades in Sorangium and Byssovorax. The tree also shows the position of clone-derived sequences from uncultured bacteria (boldface). Labilithrix luteola $\mathrm{B} 00002^{\mathrm{T}}$ was used as an outgroup to root the tree. Bootstrap values greater than $50 \%$ are shown at the nodes based on 1000 replications. The GenBank accession numbers are indicated in parenthesis. The bar represents 20 nucleotide substitutions per 1000 sites.

in the future.

The uncultured myxobacteria in Sorangium and Byssovorax clades are likely sharing distinct features with these genera. Since they are also located in Polyangiaceae family, phenotypically they are expected to share the same cigar-shaped vegetative cell-type capable of agar degradation. They are also presumed to produce swarms (as bands or pseudoplasmodia) that can penetrate the agar and at the same time capable of degrading cellulose. In addition, these uncultured strains may be hypothesized to require longer incubation time, thus can be recognized by their colonies and fruiting bodies after weeks or months of cultivations. All these characteristics may be considered in the isolation of these new potential species in the Sorangium and Byssovorax clades.

\section{Concluding remarks and future research direction}

This phylogenetic study based on metagenome data shows that there are at least several potentially new species of cellulose -degrading myxobacteria in Sorangium and Byssovorax clades. Candidate new genera related to Sorangium and Byssovorax can also be discovered and isolated in the future. Since they are currently inaccessible and only known to-date as "uncultured bacteria", we speculate they share phenotypic characteristics with currently known cellulolytic myxobacteria, and we hope that this will serve as a guide in bringing them to laboratory cultivations. Some motivations for isolating these groups of "uncultured cellulolytic myxobacteria" apart from expanding the taxonomic diversity are probably due to their medical and industrial applications to discover new anti-infectives and anticancer drugs. 


\section{Literature Cited}

Ceja-Navarro, J.A., F.N. Rivera, L. Patiño-Zúñiga, B. Govaerts, R. Marsch, A. Vila-Sanjurjo \& L. Dendooven, 2010. Molecular characterization of soil bacterial communities in contrasting zero tillage systems. Plant and Soil, 329: 127137.

Chen, Y., X. Wen, Y. Sun, J. Zhang, W. Wu \& Y. Liao, 2014. Mulching practices altered soil bacterial community structure and improved orchard productivity and apple quality after five growing seasons. Scientia Horticulturae, 172: 248-257.

Dawid, W., 2000. Biology and global distribution of myxobacteria in soils. FEMS Microbiology Reviews, 24: 403-427.

Drews, G. 1974. Mikrobiologisches Praktikum, 2nd ed. Springer, Berlin.

Elshahed, M.S., N.H. Youssef, A.M. Spain, C. Sheik, F.Z. Najar, L.O. Sukharnikov, B.A. Roe, J.P. Davis, P.D. Schloss, V.L. Bailey \& L.R. Krumholz, 2008. Novelty and uniqueness patterns of rare members of the soil biosphere. Applied Environmental Microbiology, 74:5422-5428.

Fudou, R., Y. Jojima, T. Iizuka, \& S. Yamanaka, 2002. Haliangium ochraceum gen. nov., sp. nov. and Haliangium tepidum sp. nov.: novel moderately halophilic myxobacteria isolated from coastal saline environments. Journal of General Applied Microbiology, 48:109-116.

Garcia, R. O., D. Krug \& R. Müller, 2009. Discovering natural products from myxobacteria with emphasis on rare producer strains in combination with improved analytical methods. In: Hopwood, D. (ed.), Methods in enzymology: complex enzymes in microbial natural product biosynthesis, vol. 458, part A, Academic Press, Burlington. pp. 59-91.

Garcia, R., K. Gerth, M. Stadler, I.J.Jr. Dogma \& R. Müller, 2010. Expanded phylogeny of myxobacteria and evidence for cultivation of the unculturables. Molecular Phylogenetics and Evolution, 57:878-887.

Garcia, R., D. Pistorius, M. Stadler \& R. Müller, 2011. Fatty acid related phylogeny of myxobacteria as an approach to discover polyunsaturated omega 3/6 fatty acids. Journal of Bacteriology, 193: 1930-1942.

Garcia, R. \& R. Müller, 2014. The family Polyangiaceae. In: Rosenberg E., E.F. DeLong, S. Lory, E. Stackebrandt, F. Thompson (ed.), The Prokaryotes: Deltaproteobacteria and Epsilonproteobacteria, 4th ed., vol. 10, Springer, Heidelberg. pp. 247-279.

Garcia, R., M. Stadler, K. Gemperlein \& R. Müller, 2016. Aetherobacter fasciculatus gen. nov., sp. nov. and
Aetherobacter rufus sp. nov., novel myxobacteria with promising biotechnological applications. International Journal of Systematic and Evolutionary Microbiology, 66: 928-938.

Garcia, R. \& R. Müller, 2018. Simulacricoccus ruber gen. nov., sp. nov., a microaerotolerant, non-fruiting, myxosporeforming soil myxobacterium and emended description of the family Myxococcaceae. International Journal of Systematic and Evolutionary Microbiology, 68: 3101-3110.

Gawas, D., R. Garcia, V. Huch \& R. Müller, 2011. A highly conjugated dihydroxylated $\mathrm{C}_{28}$ steroid from a myxobacterium. Journal of Natural Products, 74: 12811283.

Gemperlein, K., S. Rachid, R.O. Garcia, S.W. Wenzel \& R. Müller, 2014. Polyunsaturated fatty acid biosynthesis in myxobacteria: different PUFA synthases and their product diversity. Chemical Science, 5: 1733-1741.

Iizuka, T., Y. Jojima, R. Fudou \& S. Yamanaka, 1998. Isolation of myxobacteria from the marine environment. FEMS Microbiology Letters, 169: 317-322.

Iizuka, T., Y. Jojima, R. Fudou, A. Hiraishi, J.W. Ahn \& S. Yamanaka, 2003a. Plesiocystis pacifica gen. nov., sp. nov., a marine myxobacterium that contains dihydrogenated menaquinone, isolated from the pacific coasts of Japan. International Journal of Systematic and Evolutionary Microbiology, 53: 189-195.

Iizuka, T., Y. Jojima, R. Fudou, M. Tokura, A. Hiraishi \& S. Yamanaka, 2003b. Enhygromyxa salina gen. nov., sp. nov., a slightly halophilic myxobacterium isolated from the coastal areas of Japan. Systematic and Applied Microbiology, 26: 189-196.

Iizuka, T., Y. Jojima, A. Hayakawa, S. Fujii, S. Yamanaka \& R. Fudou, 2013. Pseudoenhygromyxa salsuginis gen. nov., sp. nov., a myxobacterium isolated from an estuarine marsh. International Journal of Systematic and Evolutionary Microbiology, 63: 1360-1369.

Jansen, R., A. Nowak, B. Kunze, H. Reichenbach, \& G. Höfle, 1995. Four new carotenoids from Polyangium fumosum (Myxobacteria): 3,3',4,4'-tetradehydro-1,1',2,2'-tetrahydro$1,1^{\prime}$-dihydroxy- $\psi, \psi$-carotene (Di- $O$-demethylspirilloxanthin), its $\beta$-glucoside and glucoside fatty acid esters. Liebigs Annalen, 1995: 873-876.

Kohl, W., A. Gloe \& H. Reichenbach, 1983. Steroids from the myxobacterium Nannocystis exedens. Journal of General Microbiology, 129: 1629-1635.

Kong, H.H., J. Oh, C. Deming, S. Conlan, E.A. Grice, M.A. Beatson, E. Nomicos, E.C. Polley, H.D. Komarow, NISC Comparative Sequence Program, P.R. Murray, M.L. Turner \& J.A. Segre, 2012. Temporal shifts in the skin microbiome 
associated with disease flares and treatment in children with atopic dermatitis. Genome Plant Research, 22: 850859.

Kunze, B., R. Jansen, L. Pridzun, E. Jurkiewicz, G. Hunsmann, G. Höfle \& H. Reichenbach, 1993. Thiangazole, a new thiazoline antibiotic from Polyangium sp. (Myxobacteria): production, antimicrobial activity and mechanism of action. Journal of Antibiotics, 46:1752-1755.

Kunze, B., H. Steinmetz, G. Höfle, M. Huss, H. Wieczorek \& H. Reichenbach, 2006. Cruentaren, a new antifungal salicylate-type macrolide from Byssovorax cruenta (Myxobacteria) with inhibitory effect on mitochondrial ATPase activity. Fermentation and biological properties. Journal of Antibiotics, 59: 664-668.

Kunze B., F. Sasse, H. Wieczorek \& M. Huss. 2007. Cruentaren A, a highly cytotoxic benzolactone from myxobacteria is a novel selective inhibitor of mitochondrial F1-ATPases. FEBS Letters. 581:3523-7.

Mohr, K., C. Wolf, U. Nübel, A.K. Szafrańska, M. Steglich, F. Hennessen, K. Gemperlein, P. Kämpfer, K. Martin, R. Müller \& J. Wink, 2018. A polyphasic approach leads to seven new species of the cellulose-decomposing genus Sorangium, Sorangium ambruticinum sp. nov., Sorangium arenae sp. nov., Sorangium bulgaricum sp. nov., Sorangium dawidii sp. nov., Sorangium kenyense sp. nov., Sorangium orientale sp. nov. and Sorangium reichenbachii sp. nov. International Journal of Systematic and Evolutionary Microbiology, 68: 3576-3586.

Mulzer, J.H., 2009. The epothilones: an outstanding family of anti-tumor agents, from soil to clinic. Progress in the Chemistry of Organic Natural Products. Springer-Verlag, Wien. pp.1-260.

Ojika, M., Y. Inukai, Y. Kito, M. Hirata, T. Iizuka \& R. Fudou, 2008. Miuraenamides: antimicrobial cyclic depsipeptides isolated from a rare and slightly halophilic myxobacterium. Chemistry, an Asian Journal, 3: 126-133.

Pietschmann, T., J. Gentzsch, H. Steinmetz \& B. Kunze, 2012. Haprolid and derivatives thereof as inhibitors of HCV. World Patent, WO20122110249.

Plaza, A., R. Garcia, G. Bifulco, J.P. Martinez, S. Hüttel, F. Sasse, A. Meyerhans, M. Stadler \& R. Müller, 2012. Aetheramides A and B, potent HIV-inhibitory depsipeptides from a myxobacterium of the new genus "Aetherobacter". Organic Letters, 14: 2854-2857.

Reichenbach, H., 1983. A simple method for the purification of myxobacteria. Journal of Microbiological Methods, 1: 7779.

Reichenbach, H., 2005. Order VIII. Myxococcales. Tchan, Pochon and Pre'vot 1948, 398AL. In: D.J. Brenner, N.R.
Krieg, J.T. Staley \& G.M. Garrity (ed.), Bergey's Manual of Systematic Bacteriology, $2^{\text {nd }}$ ed, vol. 2, part C, Springer, New York. pp. 1059-1144.

Reichenbach, H. \& M. Dworkin, 1992. The Myxobacteria. In: A. Balows, H.G. Trüper, M. Dworkin, W. Harder \& K.H. Schleifer (ed.), The Prokaryotes, 2nd ed, Springer, Berlin. pp. 3416-3487.

Reichenbach, H. \& H. Kleinig, 1971. The carotenoids of Myxococcus fulvus (Myxobacterales). Archiv für Mikrobiologie, 76: 364-380.

Reichenbach, H., E. Lang, P. Schumann, \& C. Spröer, 2006. Byssovorax cruenta gen. nov., sp nov., nom. rev., a cellulose-degrading myxobacterium: rediscovery of 'Myxococcus cruentus' Thaxter 1897. International Journal of Systematic and Evolutionary Microbiology, 56: 23572363.

Sanford, R., J. Cole \& J. Tiedje, 2002. Characterization and description of Anaeromyxobacter dehalogenans gen. nov., sp. nov., an aryl-halorespiring facultative anaerobic myxobacterium. Applied Environmental Microbiology, 68: 893-900.

Shimkets, L.J., M. Dworkin \& H. Reichenbach, 2006. The Myxobacteria. In: Dworkin, M., S. Falkow, E. Rosenberg, K.H. Schleifer \& E. Stackerbrandt (ed.), The Prokaryotes: a Handbook on the Biology of Bacteria, $3^{\text {rd }}$ ed., vol. 7, Springer, New York. pp. 31-115.

Steinmetz, H., J. Li, C. Fu, N. Zaburannyi, B. Kunze, K. Harmrolfs, V. Schmitt, J. Herrmann, H. Reichenbach, G. Höfle, M. Kalesse \& R. Müller. 2016. Isolation, structure elucidation, and (bio)synthesis of Haprolid, a cell-typespecific myxobacterial cytotoxin. Angewandte Chemie International Edition. 55:10113-10117.

Tringe S.G., C. von Mering, A. Kobayashi, A.A. Salamov, K. Chen, H.W. Chang, M. Podar, J.M. Short, E.J. Mathur, J.C. Detter, P. Bork, P. Hugenholtz \& E.M. Rubin , 2005. Comparative metagenomics of microbial communities. Science, 308: 554-7.

Williamson, K.E, J. Kan, S.W. Polson \& S.J. Williamson, 2011. Optimizing the indirect extraction of prokaryotic DNA from soils. Soil Biology and Biochemistry, 43: 736-748.

Youssef, N., C.S. Sheik, L.R. Krumholz, F.Z. Najar, B.A. Roe \& M.S. Elshahed, 2009. Comparison of species richness estimates obtained using nearly complete fragments and simulated pyrosequencing-generated fragments in $16 \mathrm{~S}$ rRNA gene-based environmental surveys. Applied Environmental Microbiology, 75: 5227-5236.

Zeggel, B., 1993. Steroide bei Myxobakterien. Thesis: Technische Universität Carolo-Wilhelmina zu Braunschweig, pp. 1-134. 